\title{
Erratum to: The role of subjective beliefs in preferences for redistribution
}

\author{
Lionel Page $^{1}$ (D) Daniel G. Goldstein ${ }^{2}$
}

Published online: 29 March 2016

(C) Springer-Verlag Berlin Heidelberg 2016

\section{Erratum to: Soc Choice Welf DOI 10.1007/s00355-015-0945-9}

The version that was initially posted online was not the correct version of the paper. The correct version has now replaced it.

The online version of the original article can be found under doi:10.1007/s00355-015-0945-9.

$凶 \quad$ Lionel Page

lionel.page@qut.edu.au

Daniel G. Goldstein

dgg@microsoft.com

1 Queensland University of Technology, 2 George Street, Brisbane 4000, Australia

2 Microsoft Research, 641 Avenue of the Americas, New York, NY 10011, USA 